\title{
Identification of the drug-use behaviors of the elderly living in nursing homes
}

This article was published in the following Dove Press journal:

Clinical Interventions in Aging

\section{Ayse Ferdane Oguzoncul' \\ Emel Ercan ${ }^{2}$ \\ Evrim Celebi ${ }^{3}$}

'Department of Public Health, Faculty of Medicine, Fırat University, Elazig, Turkey; ${ }^{2}$ Department of Public Health, Faculty of Medicine, Firat University Hospital, Elazig, Turkey; ${ }^{3}$ Faculty of Health Sciences, Firat University, Elazig, Turkey
Correspondence: Ayse Ferdane Oguzoncul

Department of Public Health, Faculty of Medicine, Firat University, Floor 3, 23119 Elazig, Turkey Tel +904242370000 ext 4685 Email foguzoncul@firat.edu.tr
Objective: As our society ages, the incidence of acute and chronic diseases increases, and so does chronic drug use and polypharmacy. This study was intended to examine the medication behaviors of the elderly who lived in the nursing homes in the Elazig and Malatya provinces, located in eastern Turkey, and in the Kayseri province located in Central Anatolia.

Materials and methods: The population of this cross-sectional study included people over the age of 60 years $(n=310)$ who lived in the nursing homes in the Elazig, Malatya, and Kayseri provinces. The entire population was included in the research without sampling, of which 255 (82.2\%) people participated. Data were collected using a survey form, and the survey was conducted through face-to-face interviews. The data were reported in numbers, percentages, and averages. Results: Of the studied population, $87.8 \%$ were treated through polypharmacy, using various drugs. The most commonly used drugs were antihypertensives (52.2\%). Females over 60 years used more polypharmacy than men $(p<0.05)$. Of the elderly studied, $97.3 \%$ used drugs as recommended, $95.3 \%$ did not know about the side effects of the drugs they used, and $93.7 \%$ did not read the prospectuses of the drugs. Also, $82.7 \%$ stated that their drugs did not have any side effects and $70.2 \%$ said that the health care personnel did not educate them about their drugs. Of the elderly who were informed about their drugs, $55.3 \%$ obtained the information from the nurse and $44.7 \%$ from the physician. Of the elderly, $51.3 \%$ received education on the duration they would need to take the drug, $30.3 \%$ were educated on the intended use of the drugs, $7.9 \%$ received education on their drug dose, and $6.6 \%$ were educated on the side effects of the drugs.

Conclusion: The results of this study showed that the majority of the elderly studied used more than one drug (polypharmacy) and the most used drug group was antihypertensives.

Keywords: elderly, nursing home, drug-use

\section{Introduction}

The World Health Organization (WHO) categorizes people aged 45-59 years as middle aged, 60-74 years as elderly, 75-89 years as old, and 90 years and over as very old. ${ }^{1}$ The old population in Turkey increases more rapidly than the population of the other age groups. Although Turkey, which is in the process of a global aging called "demographic transition", seems to have a relatively younger population, it has quite a high number of absolutely old people. According to the data obtained in 2014, the segment of the population which is 65 years of age or older is $8.0 \%$. Population projections predict that the number of people within the old population in Turkey will increase by $10.2 \%$ by 2023 , and by $20.8 \%$ by $2050 .^{2}$

The increase in the elderly population, along with an increase in life expectancy, has raised more concerns regarding the problems of this population. Coexistence of multiple diseases in the elderly is the leading health problem specific to this time of life, and age-associated diseases are expected to increase by $10 \%$ annually. ${ }^{3-5}$ Pharmacological 
approaches play an important role in managing the chronic diseases in the elderly. ${ }^{6}$ Within the general population, elderly people make up a significant segment of those taking drugs. The higher the prevalence of chronic diseases, the more drugs the old individual has to use. Also, the cost of drugs increases with the age of the individual. However, sociodemographic factors, such as age, gender, and education, play an important role in drug requirement and use..$^{7-10}$

Polypharmacy, as addressed in most studies, could be defined as the use of more medicines than the clinically required ones or the use of five or more medications at the same time during treatment. It is a health problem that is more common and significant during old age and especially harmful when the patient uses multiple drugs or high dosage of drugs for a long time. Because of the illnesses that require more and long-term medications for old people, polypharmacy increases with age. ${ }^{11}$ Previous research shows that almost $50 \%$ of the old adults use one or more drugs, even when this is not medically necessary. ${ }^{8}$ Other crucial factors for polypharmacy include: 1) elderly people being familiar with their drugs, 2) being able to procure them, 3) good communication between the patient and the doctor/nurse, 4) the frequency of receiving medical consultation, 5) patients' levels of knowledge about their drugs, and 6) their adherence to the recommended dose. ${ }^{6}$ The fact that there is no adequate information about the ageassociated pharmacodynamic and pharmacokinetic effects caused by drugs, polypharmacy, side effects of drugs, and high cost of drugs, as well as the fact that health care personnel do not receive adequate education about geriatric treatment and care, raises the importance of drug use in the elderly. ${ }^{12,13}$

This research was intended to identify the medication behaviors of the elderly who lived in the nursing homes in the Elazig and Malatya provinces located in eastern Turkey and the Kayseri province located in Central Anatolia.

\section{Materials and methods}

The population of this cross-sectional research included people over the age of $60(n=310)$ who lived in the nursing homes in the Elazig, Malatya, and Kayseri provinces. The study, which was conducted without sampling, included 255 people (82.2\%) who agreed to participate in the research. Of the population, 55 people were excluded from the research due to declining the interview, failure to cooperate, and visual and auditory dysfunction that would hinder communication. Data were collected using a survey form which was prepared through a literature review. The participants had been informed about the survey and the research beforehand, and the survey was completed by the researcher through face-to-face interviews. Written informed consent was obtained from the participants.

The relevant drugs were classified based on Nobili et al's "Anatomical Therapeutic Chemical Classification System". ${ }^{14}$ The symptoms and side effects of the relevant drugs were questioned based on the patients' expressions.

The study was approved by the Research Ethics Committee of Frrat University Faculty of Medicine Non-interventional Clinical Researches Ethics Board and the Turkish Social Service and Children Protection Institution (Sosyal Hizmetler ve Çocuk Esirgeme Kurumu, SHÇEK).

After the necessary permissions had been obtained, the fieldwork of the research was completed in three months between April and June of 2010.

The obtained data were evaluated using a statistical software package and expressed in numbers and percentages, and $p<0.05$ was regarded to be significant.

\section{Results}

The mean age of the elderly $(\mathrm{N}=255)$ included in this study was 72.70 \pm 8.26 years (min: 60, max: 100), and it was determined to be $72.99 \pm 9.31$ years (min: 60, max: 100) for males and 72.55 7.65 years (min: 60, max: 95) for females.

Of the old people studied, $64.7 \%$ were males, $38.5 \%$ had graduated from an educational institution, and $36.5 \%$ did not have any social security.

The most widely used drugs by the elderly who participated in the study were as follows: antihypertensive drugs (52.2\%), analgesic and anti-inflammatory drugs (43.1\%), gastrointestinal tract drugs $(20.8 \%)$, and cardiovascular system drugs (14.9\%) (Table 1).

Of the elderly who participated in the study, $87.8 \%(n=224)$ were treated through polypharmacy and $98.4 \%$ reported that

Table I Distribution of the drugs used by the elderly included in the research

\begin{tabular}{lll}
\hline Drug classes & Number & $\%$ \\
\hline $\begin{array}{l}\text { Analgesic and anti-inflammatory } \\
\text { (musculoskeletal) drugs }\end{array}$ & $\mathrm{II} 3$ & 44.1 \\
Antibiotics & 9 & 3.5 \\
Antihypertensive drugs & 127 & 53.2 \\
Gastrointestinal tract drugs & 53 & 20.8 \\
Cardiovascular system drugs & 38 & 14.9 \\
Respiratory tract drugs & 36 & 14.1 \\
Ophthalmic preparations & 10 & 3.9 \\
Otic preparations & $\mathrm{I}$ & 0.4 \\
Psychiatric drugs & 23 & 9.0 \\
Central nervous system drugs & 5 & 2.0 \\
\hline
\end{tabular}

Notes: Multiple answers were given for the questions. The percentages were calculated using " $n$ " scores. 
Table 2 Distribution of drug-use behaviors of the elderly included in the research by gender

\begin{tabular}{|c|c|c|c|}
\hline \multirow[t]{3}{*}{ Number of drugs } & \multicolumn{3}{|l|}{ Gender } \\
\hline & Female & Male & Total \\
\hline & Number (\%) & Number (\%) & Number (\%) \\
\hline People using one drug & $3(3.4)$ & $28(17.0)$ & $31(12.2)$ \\
\hline $\begin{array}{l}\text { People using two to } \\
\text { four drugs }\end{array}$ & $48(53.3)$ & $109(66.0)$ & $157(6 \mid .6)$ \\
\hline $\begin{array}{l}\text { People using five or } \\
\text { more drugs }\end{array}$ & $39(43.3)$ & $28(17.0)$ & $67(2.62)$ \\
\hline Total & $90(35.3)$ & $165(64.7)$ & $255(100.0)$ \\
\hline
\end{tabular}

Note: $\chi^{2}=25.84 ; S D=2 ; p<0.05$.

their drugs had been recommended by the physician. Of the elderly, $97.3 \%$ used their drugs as recommended.

A higher proportion of females were used through polypharmacy than males $(p<0.05)$.

Table 2 indicates the distribution of drug-use behaviors of the elderly who participated in the research by gender.

Of the elderly, 95.3\% reported that they did not know about the side effects of their drugs (Table 3).

Of the elderly who participated in the study, $93.7 \%$ $(n=239)$ did not read the prospectuses of the drugs. Table 4 indicates the reasons for the elderly people not reading the prospectuses. Of the elderly, $41.2 \%$ considered reading prospectuses to be unnecessary.

Of the elderly, $82.7 \%$ reported that their drugs did not have any side effects (Table 5).

Of the elderly, $70.2 \%$ reported that the health care personnel had not informed them about the drugs they used (Table 6).

Of the elderly who were informed about the drugs they used, $55.3 \%$ obtained the information from the nurse and $44.7 \%$ from the physician (Table 7).

Of the elderly, $51.3 \%(n=39)$ received education on the duration of drug use, $30.3 \%(n=23)$ were educated on the intended use of the drugs, $7.9 \%(\mathrm{n}=6)$ received education on their drug dose, and $6.6 \%(\mathrm{n}=5)$ were educated on the side effects of the drugs.

\section{Discussion}

In the present study, antihypertensive drugs ranked first and analgesic and anti-inflammatory drugs ranked second among

Table 3 Distribution of the drugs used by the elderly included in the research by knowing about side effects

\begin{tabular}{lll}
\hline $\begin{array}{l}\text { Knowing about side } \\
\text { effects }(\mathbf{N}=\mathbf{2 5 5})\end{array}$ & Number & $\%$ \\
\hline Yes & 12 & 4.7 \\
No & 243 & 95.3 \\
\hline
\end{tabular}

Table 4 Distribution of the elderly included in the research by their reasons for not reading prospectuses

\begin{tabular}{lll}
\hline $\begin{array}{l}\text { Reasons for not reading } \\
\text { prospectuses }(\mathbf{n}=\mathbf{2 3 9})\end{array}$ & Number & $\%$ \\
\hline Not understanding the words & 76 & 29.8 \\
Visual impairment & 16 & 6.3 \\
Illiteracy & 43 & 16.5 \\
Considering this activity to & 104 & 41.2 \\
be unnecessary & & \\
\hline
\end{tabular}

the drug classes used by the elderly (Table 1). Previous studies also suggested that antihypertensive drugs ranked first among the drug classes used by the elderly, and they were followed by analgesic drugs and endocrine system drugs. ${ }^{12,15}$ These results are in accord with the findings of the present study. Since hypertension is widely observed among the elderly, it is expected that antihypertensive drugs rank first. Also, the fact that the occurrence of diseases such as osteoarthritis increases with age explains why analgesic and anti-inflammatory drugs rank second. A study on the old population conducted in a different country suggested that the most widely used drugs included antihypertensive, antiarrhythmic, hypnotic, and sedative drug classes. ${ }^{10}$

The present study found that the rate of polypharmacy was higher among the female elderly (43.3\%) than that of the male elderly $(p<0.05)$. Similar results were achieved in the studies conducted by Arslan et $\mathrm{al}^{7}$ and Seçkin et al. ${ }^{16}$ There was no significant difference in the average age between the genders. The difference between the findings related to genders was the result of the responsibilities of females regarding status in social life, childbearing, and maternity.

Of the elderly who participated in the study, $87.8 \%$ were treated through polypharmacy. According to a study conducted by Arslan et al in the nursing homes located in 23 provinces, $71.8 \%$ of the elderly were treated through polypharmacy. ${ }^{7}$ The studies conducted by Seçkin et al, ${ }^{16}$ Bayik et al,${ }^{17}$ and Disçigil et al ${ }^{18}$ found that polypharmacy was widely observed. de Oliveira and Novaes ${ }^{10}$ determined that each elderly person used five drugs, on average. These findings were compatible with the present study. The epidemiological studies found that polypharmacy among

Table 5 Distribution of the drugs used by the elderly included in the research by drugs causing side effects

\begin{tabular}{lll}
\hline $\begin{array}{l}\text { Drugs causing side } \\
\text { effects }(\mathbf{N}=\mathbf{2 5 5})\end{array}$ & Number & $\%$ \\
\hline Yes & 44 & 17.3 \\
No & 211 & 82.7 \\
\hline
\end{tabular}


Table 6 Distribution of the elderly included in the research by being provided with information about the drugs they used by the health care personnel

\begin{tabular}{lll}
\hline $\begin{array}{l}\text { Being provided with information } \\
\text { by the health care personnel }\end{array}$ & Number & $\%$ \\
\hline Provided information & 76 & 29.8 \\
Did not provide information & 179 & 70.2 \\
\hline
\end{tabular}

the elderly was three or four times more common than it was among the young population. This frequency of polypharmacy increased drug interaction risks as well as adverse effects. ${ }^{12}$

According to the present study, $98.4 \%$ of the elderly took drugs on the advice of the physician. The study conducted by Bayik et $\mathrm{a}^{17}$ found that $84.2 \%$ of the elderly continued to consistently use a drug on the advice of the physician. This is because the elderly in nursing homes are always under the supervision of a physician. They can easily consult the physician. And if necessary, they can take their drugs on time and without skipping a dose under the nurse's supervision. However, in various studies done in our country, it is important that medicines are taken at the appropriate dose and during the period recommended by the physician, unless the medicines are taken without consulting the medicines of the patients in our country or storing medicines at home. Storing medicines at home or similar complaints were found to be common non-rational drug use problems. ${ }^{19}$

In the present study, almost all (97.3\%) of the elderly living in the nursing homes took the recommended dose of drugs. A study conducted by Ozbek et $\mathrm{al}^{12}$ found that the frequency of treatment compliance among the elderly was found to be $83.0 \%$. This finding supports the present study. The reason why the elderly comply with treatment can be associated with the fact that they are provided with adequate professional support for regular drug use. Erturk ${ }^{20}$ found that $74.0 \%$ of the elderly did not take their drugs as recommended. Age-associated physical defects and various accompanying chronic diseases affected the drug-use behaviors of the elderly in this study.

Of the elderly, 95.3\% did not know about the side effects of drugs they used. Similarly, another study reported a high

Table 7 Distribution of the elderly included in the research by health care personnel giving information about the drugs used

\begin{tabular}{lll}
\hline People giving information & Number & $\%$ \\
\hline Physician & 34 & 44.7 \\
Nurse & 42 & 55.3 \\
\hline
\end{tabular}

rate as well regarding this relevant issue..$^{13}$ Eski and Pinar $^{21}$ found that a high proportion (94.2\%) of the elderly did not know about the side effects of the drugs. This finding is in accord with our study. Thus, the elderly did not have adequate information about the side effects of the drugs they used.

Of the elderly included in the research, $93.7 \%$ did not read prospectuses. Solmaz and Akin ${ }^{15}$ found that $80.8 \%$ did not read prospectuses, and Arslan and Eser $^{22}$ found that $81.7 \%$ did not read prospectuses. These findings support the present study. Of the elderly who did not read prospectuses, $41.2 \%$ did not consider this activity to be necessary, $29.8 \%$ did not understand the words, $16.5 \%$ were illiterate, and $6.3 \%$ had visual impairment. Solmaz and Akin ${ }^{15}$ and Arslan et al ${ }^{7}$ reported similar results. Based on these findings, the text of the prospectuses, except for their terminological meanings, should be expressed in a plain language. The research findings also showed that a great majority of the elderly did not consider reading prospectuses to be necessary.

The present study found that the drugs used by the elderly did not cause any side effects (82.7\%). Similarly, in the study conducted by Arslan et al, $73.3 \%$ of the elderly reported that their drugs did not cause any side effects. On the other hand, in the study conducted by Solmaz and Akin, ${ }^{15} 90.8 \%$ of the elderly reported that their drugs did cause side effects. This finding is not in accord with the present study. The differences among the research findings may be the result of the individual characteristics of the elderly, their diagnoses, the number of drugs they used, and the drug types.

In the present study, $70.2 \%$ of the elderly did not obtain information about the drugs they used from the health care personnel. Similar to the present study, the study conducted by Eski and Pinar ${ }^{21}$ found that $62.5 \%$ of the elderly were not informed about the drugs they used. On the contrary, high rates of obtaining information about the drugs used by the elderly were observed in the studies conducted by Solmaz and Akin $^{15}$ and Dolu. ${ }^{23}$

In the present study, of the elderly who received information about the drugs they used, 55.3\% obtained the information from the nurse and $44.7 \%$ from the physician. Hacihasanoğlu et $\mathrm{al}^{24}$ reported that $65.0 \%$ of the elderly obtained this information from the nurse and the physician. The results of the previous studies were unlike that of the present study. This information was found to be provided mostly by the physicians..$^{22,23}$

\section{Study limitations}

The prevalence of disability and chronic disease is higher among the individuals living in nursing homes than the 
individuals living in other segments of society. Therefore, this study may not represent the drug use among the elderly living outside of nursing homes. Since the occupancy rate in the nursing homes located in the study region is low, the number of subjects also comprises a limitation of the study. In addition, the fact that we cannot know if nursing home residents remember or not the medication they have and we cannot evaluate their knowledge level about the side effects of the medication is among the other limitations.

\section{Conclusion and suggestions}

The results of this study showed that the majority of the elderly studied used more than one drug (polypharmacy) and the most used drug group was antihypertensives.

The study concluded that the elderly should be under the supervision of the nurses in order to be compliant with taking drugs, and for understanding why the drugs are given. This is important because the majority of the elderly are treated through polypharmacy. They should be informed by the physician and the nurse about the importance of drug use in the treatment of their diseases. Also, the text of the prospectuses and that on drug containers should be printed in large fonts so that they can be read by the elderly. Drug companies should use words that the elderly can understand. Also, the elderly should be educated on the importance of reading the prospectus.

\section{Author contributions}

Dr Ayse Ferdane Oguzoncul provided her experience on data analysis and advised throughout the study. She did data crunching and evaluation, and commented on the results. Ms. Emel Ercan did surveying on the field and data analysis, and wrote the manuscript together with Dr Oguzoncul. Dr Evrim Celebi participated in writing both the manuscript and the proposal. All authors contributed toward data analysis, drafting, and critically revising the paper, and agree to be accountable for all aspects of the work.

\section{Disclosure}

The authors report no conflicts of interest in this work.

\section{References}

1. World Health Organization (WHO). Definition of an Older or Elderly Person, 2002. Available from: http://www.who.int/healthinfo/survey/ ageingdefnolder/en. Accessed June 15, 2016.

2. Turkish Statistical Institute. Elderly statistics 2014. Publication number 4365. Ankara: Turkish Statistical Institute; 2014 [cited February 20 , 2016]. Available from: www.tuik.gov.tr. Accessed June 15, 2016.
3. Cicolini G, Comparcini D, Flacco ME, Capasso L, Masucci C, Simonetti V. Self-reported medication adherence and beliefs among elderly in multi-treatment: a cross-sectional study. Appl Nurs Res. 2016;30: 131-136.

4. Ellidokuz H, Ellidokuz E, Ucku R, Aydin U. Evaluation of the health status of the elderly living in institutions and at home. J Health Soc. 2005; $15: 40-44$

5. Guner P, Guler C. Home safety of older people and check lists. Turk $J$ Geriatr. 2002;5:150-154.

6. Topbas M, Yaris F, Can G. Do the elderly have adequate information about the drugs they use?: results of a study conducted in a primary health care in Trabzon. Ege J Med. 2003;42:85-90.

7. Arslan S, Atalay A, Kutsal YG. Drug use in elderly. Turk J Geriatr. 2000;3:56-60.

8. Nechba RB, Kadiri MEMB, Bennani-Ziatni M, Zeggwagh AA, Mesfioui A. Difficulty in managing polypharmacy in the elderly: case report and review of the literature. J Clin Gerontol Geriatr. 2015;6(1): $30-33$.

9. Santalucia P, Franchi C, Djade CD, et al. Gender difference in drug use in hospitalized elderly patients. Eur J Intern Med. 2015;26(7):483-490.

10. de Oliveira MPF, Novaes MRCG. Drug-related problems in institutionalized elderly in Brasilia, Brazil. Biomed Aging Pathol. 2011; 1(3):179-184.

11. Arslan GG, Eser I. The effect of education given in drug use adaptation in the elderly. Turk J Geriatr. 2005;8:134-140.

12. Ozbek S, Kaya E, Tekin A, Dogan S. Medication compliance in elderly. Turk J Geriatr. 2006;9:177-181.

13. Akici A, Kalaca S, Ugurlu MU, Çal ${ }_{1} \mathrm{~S}$, Oktay S. Evaluation of rational drug use of general practitioners' in management of elderly patients. Turk J Geriatr. 2001;4:100-105.

14. Nobili A, Tettamanti M, Frattura L. Drug use by the elderly in Italy. Ann Pharmacother. 1997;31:416-422.

15. Solmaz T, Akin B. Medication use and ability of self-medication use in elderly living at home. Turk J Geriatr. 2009;12:72-81.

16. Seçkin Ü, Bodur H, Kutsal YG. Drug use in elderly. Turk J Geriatr. 1998;1:36-38.

17. Bayik A, Ozgür G, Ozsoy SA, et al. Physical health problems and drug using behaviors related to chronical diseases of the residents living in nursing home. Turk J Geriatr. 2002;5:68-74.

18. Disçigil G, Tekinc N, Anadol Z, Bozkaya AO. Polypharmacy in nursing home and community-dwelling elderly. Turk J Geriatr. 2006;9(3):117-121.

19. Vancelik S, Calikoglu O, Guraksin A, Beyhun E. Rational drug use behaviors and related factors of adults living in city centre of Erzurum. Bull Commun Med. 2006;25(2):33-38.

20. Erturk A. Misuse of Drugs by the Elderly Living in Nursing Homes and the Prognostic Factors [master's thesis]. Sivas: Cumhuriyet University, Institute of Health Sciences, Department of Nursing; 2005.

21. Eski O, Pinar R. A study on the cardiovascular drug misuses of elderly people with cardiovascular problems. Turk J Geriatr. 2005;8: 141-147.

22. Arslan GG, Eser I. Self-medication adaptation of the elderly and the role of the nurse. Journal of Ege University Nursing Faculty. 2005;29: $147-157$.

23. Dolu CI. Identification of the Information and Practices about Drug Use by Elderly Individuals [master's thesis]. Ankara: Gazi University, Institute of Health Sciences, Department of Nursing; 2008.

24. Hacihasanoğlu R, Yildirim A, Karakurt P. The effect of drug education provided to persons aged 65 or over in primary care on their drug management. Turk J Geriatr. 2010;13:99-104. 


\section{Publish your work in this journal}

Clinical Interventions in Aging is an international, peer-reviewed journal focusing on evidence-based reports on the value or lack thereof of treatments intended to prevent or delay the onset of maladaptive correlates of aging in human beings. This journal is indexed on PubMed Central, MedLine,

CAS, Scopus and the Elsevier Bibliographic databases. The manuscript management system is completely online and includes a very quick and fair peer-review system, which is all easy to use. Visit http://www.dovepress. com/testimonials.php to read real quotes from published authors. 